

\title{
Mechanical Properties and Processing Techniques of Bulk Metal- Organic Framework Glasses
}

\author{
Shichun Li ${ }^{\text {a, b}}$, René Limbach ${ }^{\text {c }}$, Louis Longley ${ }^{\text {a }}$, Amir A Shirzadi ${ }^{\text {a, d }}$, John C Walmsley ${ }^{\text {a }}$, Duncan N \\ Johnstone $^{\text {a }}$, Paul A Midgley ${ }^{\mathrm{a}}$, Lothar Wondraczek ${ }^{\mathrm{c}}$, Thomas D Bennett ${ }^{\mathrm{a} *}$. \\ a. Department of Materials Science and Metallurgy, University of Cambridge, Charles Babbage Road, Cambridge, CB3 \\ OFS, $U K$ \\ b. Institute of Chemical Materials, China Academy of Engineering Physics, Mianyang, 621900, P. R. China \\ c. Otto Schott Institute of Materials Research, University of Jena, 07743 Jena, Germany \\ d. School of Engineering and Innovation, The Open University, Milton Keynes, MK7 6AA, UK
}

\begin{abstract}
Melt quenched metal-organic framework (MOF) glasses define a new category of glass, distinct from metallic, organic and inorganic glasses, owning to dominant role of metal-ligand coordination bonding. The mechanical properties of glasses in general are of importance given their application in protective coatings, display technologies and screens, though little is known about MOFglasses in this respect. Experimental elucidation of key properties such as their scratch resistance has been limited by the lack of processing methodologies capable of producing bulk glass samples. Here, nanoindentation was used to investigate the Young's modulus and hardness of four melt-quenched glasses formed from zeolitic imidazolate frameworks (ZIF): $a_{\mathrm{g}} \mathrm{ZIF}-4, a_{\mathrm{g}} \mathrm{ZIF}-62, a_{\mathrm{g}} \mathrm{ZIF}-$ 76 and $a_{\mathrm{g}} \mathrm{ZIF}-76-\mathrm{mbIm}$. The creep resistance of the melt-quenched glasses was studied via strain-rate jump (SRJ) tests, and through constant load and hold (CLH) indentation creep experiments. Values for the strain-rate sensitivity were found to be close to those for

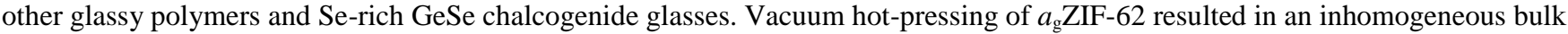
sample containing the glass and amorphous, non-melt quenched aZIF-62. Remelting and annealing however, resulted in the fabrication of a transparent, bubble-free, bulk specimen, which allowed the first scratch testing experiments to be performed on a MOF-glass.
\end{abstract}

\section{INTRODUCTION}

One family of metal-organic frameworks (MOFs), the zeolitic imidazolate frameworks (ZIFs), are a topical class of nanoporous materials formed from tetrahedral metal ions (e.g. $\left.\mathrm{Co}^{2+}, \mathrm{Zn}^{2+}, \mathrm{Li}^{+}, \mathrm{B}^{3+}, \mathrm{Mg}^{2+}\right)$, which are connected by imidazole derived ligands. ${ }^{[1,2]}$ A variety of synthetic strategies for the chemical modification of over 140 zeolitic network architectures exists, ${ }^{[3]}$ including post-synthetic modification (ligand exchange) $)^{[4]}$ and metal-ion exchange. ${ }^{[5]}$ The incorporation of multiple organic ligands during direct synthesis has led to the formation of high surface area frameworks. ${ }^{[6]}$ Several potential applications in membrane based gas separations or as shock absorbers have been suggested. ${ }^{[7-9]}$ Their chemical ${ }^{[10]}$ and mechanical ${ }^{[11]}$ properties are, however, less well documented, although the Young's modulus and hardness of single crystal ZIF samples are observed to decrease with increasing internal surface area. ${ }^{[12]}$

One member of this family, ZIF-62 $\left[\mathrm{Zn}(\mathrm{Im})_{1.75}(\mathrm{bIm})_{0.25}\right](\mathrm{Im}$ - imidazolate, $\mathrm{C}_{3} \mathrm{H}_{3} \mathrm{~N}_{2}^{-}$, bIm - benzimidazolate $\left.\left.\mathrm{C}_{7} \mathrm{H}_{5} \mathrm{~N}_{2}{ }^{-}\right),{ }^{[13}, 14\right]$ has been found to melt at ca $710 \mathrm{~K}$ in an argon atmosphere without decomposition. ${ }^{[15,16]}$ Subsequent quenching yields a

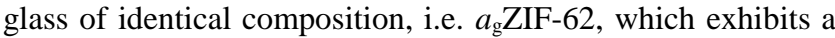
continuous network of corner-sharing $\mathrm{ZnL}_{4}$ tetrahedra $(\mathrm{L}-\mathrm{bIm}$

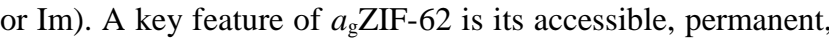
porosity towards $\mathrm{H}_{2}$ and $\mathrm{CO}_{2}$, though not $\mathrm{N}_{2} \cdot{ }^{[17]} \mathrm{MOF}$ glasses prepared by melt-quenching ZIF-76 $\quad\left[\mathrm{Zn}(\operatorname{Im})_{1.5}(\mathrm{clbIm})_{0.5}\right]$ (clbIm - 5-chlorobenzimidazole, $\mathrm{C}_{7} \mathrm{H}_{4} \mathrm{ClN}_{2}{ }^{-}$) and $\mathrm{ZIF}-76-\mathrm{mbIm}$ $\left[\mathrm{Zn}(\mathrm{Im})_{1.33}(\mathrm{mbIm})_{0.67}\right] \quad(\mathrm{mbIm}-$ 5-methylbenzimidazole,
$\mathrm{C}_{8} \mathrm{H}_{7} \mathrm{~N}_{2}{ }^{-}$) from ca. $730 \mathrm{~K}$, are also permanently porous. ${ }^{[18]}$ These reports, in conjunction with studies on glasses formed by melting hybrid coordination polymers ${ }^{[19]}$ have started to shift attention towards glassy MOFs. ${ }^{[20]}$

Current processing methodologies used to produce MOFglasses are restricted to the preparation of small glass pieces, though bulk, bubble-free samples are required for proper evaluation of their thermomechanical and optical properties. We also note that amorphous MOFs can be prepared by mechanosynthesis, ${ }^{[21]}$ or pressure, ${ }^{[22]}$ though both result in samples of micron sized grains.

At the melting point, $T_{\mathrm{m}}$, the liquid formed from ZIF-62 exhibits an extremely high viscosity, $\eta$, of $10^{5.1} \mathrm{~Pa} \cdot \mathrm{s} .{ }^{[23]}$ In inorganic glass-forming liquids, the decrease in viscosity with increasing temperature can be exploited to improve the workability of the final glass product. However, the limited thermal stability of molten ZIF-62 (decomposition temperature $T_{\mathrm{d}}$, ca $\left.823 \mathrm{~K}\right),{ }^{[16]}$ hinders this approach. Consequently, novel strategies for the preparation of MOF glasses are required. Vacuum hot-pressing, i.e. the simultaneous application of pressure and temperature, has recently been investigated for the creation of crystalline coatings with tuneable microstructures, ${ }^{[24]}$ while spark plasma sintering has been utilized to produce bulk samples of a crystalline ZIF. ${ }^{[25]}$ Small glass samples of a two-dimensional coordination polymer $\left[\mathrm{Cd}\left(\mathrm{H}_{2} \mathrm{PO}_{4}\right)_{2}(1,2,4 \text {-triazole })_{2}\right](\mathrm{CdTz})$, have also previously been obtained by ball-milling and subsequent vacuum hotpressing, of the corresponding crystalline material. ${ }^{[26]}$ 


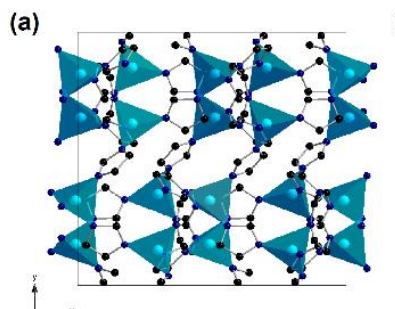

(b)
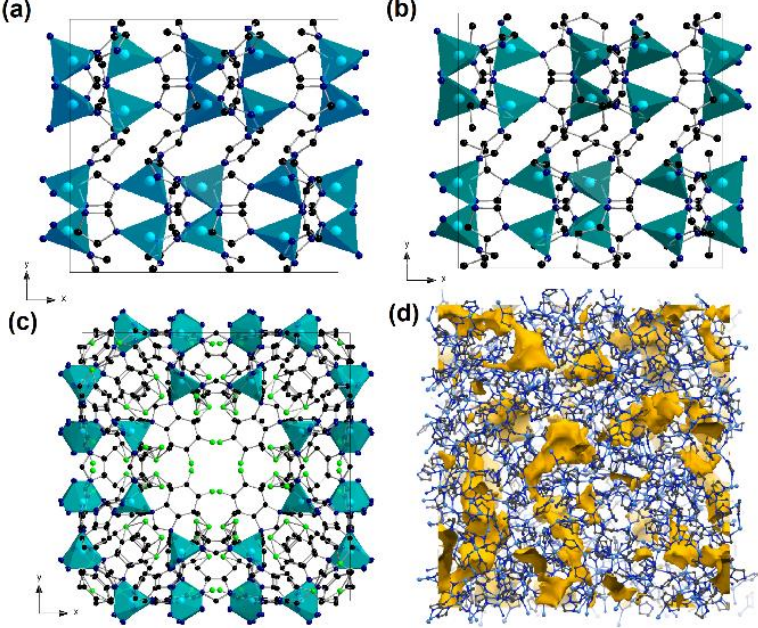

(d)

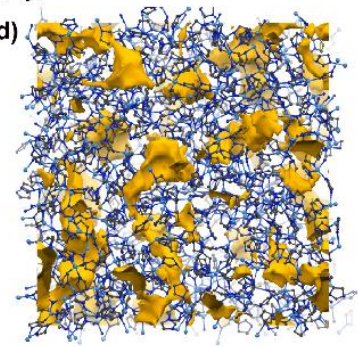

Figure 1. Unit cells viewed along c axis of (a) ZIF-4 (Pbca, $a=15.3950(17) \AA, b=15.3073(17) \AA, c=18.426(2) \AA$ ), (b) ZIF-62 (Pbca, $a=15.6620(14) \AA, b=15.6621(13) \AA, c=18.2073(19) \AA$ ),

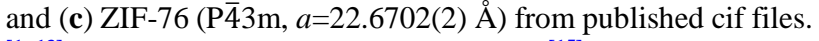
${ }^{[1,13]}$ (d) atomic configuration of $a_{\mathrm{gZIF}}-4 .{ }^{[15]} \mathrm{Zn}$, blue; N, dark blue; $\mathrm{C}$, black; $\mathrm{Cl}$, green; $\mathrm{H}$ atoms omitted. The yellow regions in (d) resemble pore volume, probe radius $1.2 \AA$.

To gain deeper insight into the mechanical properties of meltquenched MOF glasses, we investigated the mechanical behaviour of four samples formed from ZIFs: $a_{\mathrm{g}} \mathrm{ZIF}-4, a_{\mathrm{g}} \mathrm{ZIF}-$ 62, $a_{\mathrm{g} Z I F-76}$ and $a_{\mathrm{g} Z I F-76-m b I m}$ (Fig. 1, Fig. S1-S4, Table 1). Additionally, in (i) vacuum hot-pressing and (ii) remelting, two new processing routes for the fabrication of bulk MOF glasses were studied. Following this, scratch tests were performed on a MOF glass for the first time, and the results were compared to previous observations reported for inorganic and metallic glasses.

\section{RESULTS AND DISCUSSION}

\section{Mechanical properties of MOF glasses before processing}

In order to characterize the Young's modulus, E, and hardness, $H$, of the glasses, constant strain-rate nanoindentation experiments were carried out on the four melt-quenched MOF glass specimens (Fig. 2a, Fig. S5, Table 1). Within the displacement range $(400-1800 \mathrm{~nm})$, both $E$ and $H$ remain stable and independent of the indentation depth, except for

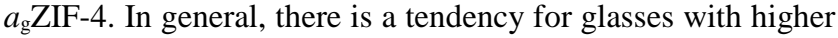
values of $E$ to also exhibit a larger $H$ and vice versa (Fig. 2b). No direct correlation has been observed between the mechanical properties ( $E$ and $H$ ) and other physical properties, such the glass transition temperature, $T_{\mathrm{g}}{ }^{\left[{ }^{[16,}{ }^{18]}\right]}$ The extremely small size of microcrystalline MOF products prevents synthesis of samples suitable for nanoindenting in a similar manner, which underscores the importance of the production of bulk melt quenched MOF glasses. $E(4.62$ and $4.08 \mathrm{GPa})$ and $H$ $(0.464$ and $0.509 \mathrm{GPa})$ values have previously been reported for the $\{111\}$ and $\{100\}$ facets of only ZIF-4 single crystals. ${ }^{[27,28]}$ The increase both $E$ and $H$ of the glass compared to the original crystalline species has previously been ascribed to the reduction in density. ${ }^{[16]}$

The strain-rate sensitivity, $m$, is a characteristic which describes the time-dependence of deformation, similar to macroscopic creep. ${ }^{[29]}$ Here, the strain-rate sensitivity was studied in a nanoindentation strain rate jump (SRJ) test ${ }^{[30]}$ and through classical constant load and hold (CLH) indentation creep experiments ${ }^{[31]}$ (Fig. S6). The values of $m$ for the meltquenched MOF glasses $(m=0.0579-0.0757)$ obtained through nanoindentation SRJ testing are in the range of polycarbonate, polysulfide and poly(methyl methacrylate) glassy polymers ( $m$ $=0.05-0.10){ }^{[32]}$ and Se-rich GeSe chalcogenide glasses with comparable hardness values, such as vitreous $\mathrm{Se}(H=0.39 \mathrm{GPa}$ and $m=0.090)$ or $\mathrm{GeSe}_{19}(H=0.57 \mathrm{GPa}$ and $m=0.0625)$ (Fig. 2c) ${ }^{[33]}$ The magnitude of $m$ in the melt-quenched MOF glasses implies a marked time dependence of the indentation response, while at the same time suggesting a rather homogeneous plastic flow behaviour. ${ }^{[34]}$

In addition to the SRJ tests, CLH indentation creep experiments were carried out on the four melt-quenched glasses (Fig. S7). Combining SRJ with CLH experiments allowed us to evaluate the creep behaviour over four orders of magnitude in the indentation strain-rate. Although the values of $m$ obtained

Table 1 Composition and properties of four melt-quenched glasses. $T_{m}$, melting point; $T_{g}$, glass transition temperature; $E$, Young's modulus; $H$, hardness; and $m$, strain rate sensitivity of indentation hardness.

\begin{tabular}{|c|c|c|c|c|c|c|c|}
\hline \multirow{2}{*}{ Name } & \multirow{2}{*}{ Composition } & $T_{m}$ (Crystal) & $T_{g}$ (Glass) & $E$ & $H$ & \multirow{2}{*}{$m^{\mathrm{a}}$} & \multirow{2}{*}{$m^{\mathrm{b}}$} \\
\hline & & $\mathrm{K}$ & $\mathrm{K}$ & $\mathrm{GPa}$ & $\mathrm{GPa}$ & & \\
\hline$a_{\mathrm{g} Z I F-4}$ & $\mathrm{Zn}(\mathrm{Im})_{2}$ & 863 & 565 & $6.89 \pm 0.10$ & $0.676 \pm 0.009$ & 0.0757 & 0.0835 \\
\hline$a_{\mathrm{g} Z I F-62}$ & $\mathrm{Zn}(\operatorname{Im})_{1.75}(\mathrm{bIm})_{0.25}$ & 710 & 591 & $6.58 \pm 0.02$ & $0.656 \pm 0.005$ & 0.0717 & 0.0822 \\
\hline$a_{\mathrm{g} Z I F-76}$ & $\mathrm{Zn}(\operatorname{Im})_{1.5}(\mathrm{clbIm})_{0.5}$ & 724 & 583 & $6.29 \pm 0.07$ & $0.682 \pm 0.010$ & 0.0630 & 0.0713 \\
\hline$a_{\mathrm{g} Z I F-76-m b I m}$ & $\mathrm{Zn}(\mathrm{Im})_{1.33}(\mathrm{mbIm})_{0.67}$ & 744 & 590 & $6.12 \pm 0.02$ & $0.658 \pm 0.006$ & 0.0579 & 0.0636 \\
\hline
\end{tabular}

a Values of $m$ as studied in a nanoindentation strain-rate jump (SRJ) test.

b Values of $m$ as derived from constant load and hold (CLH) indentation creep experiments. 

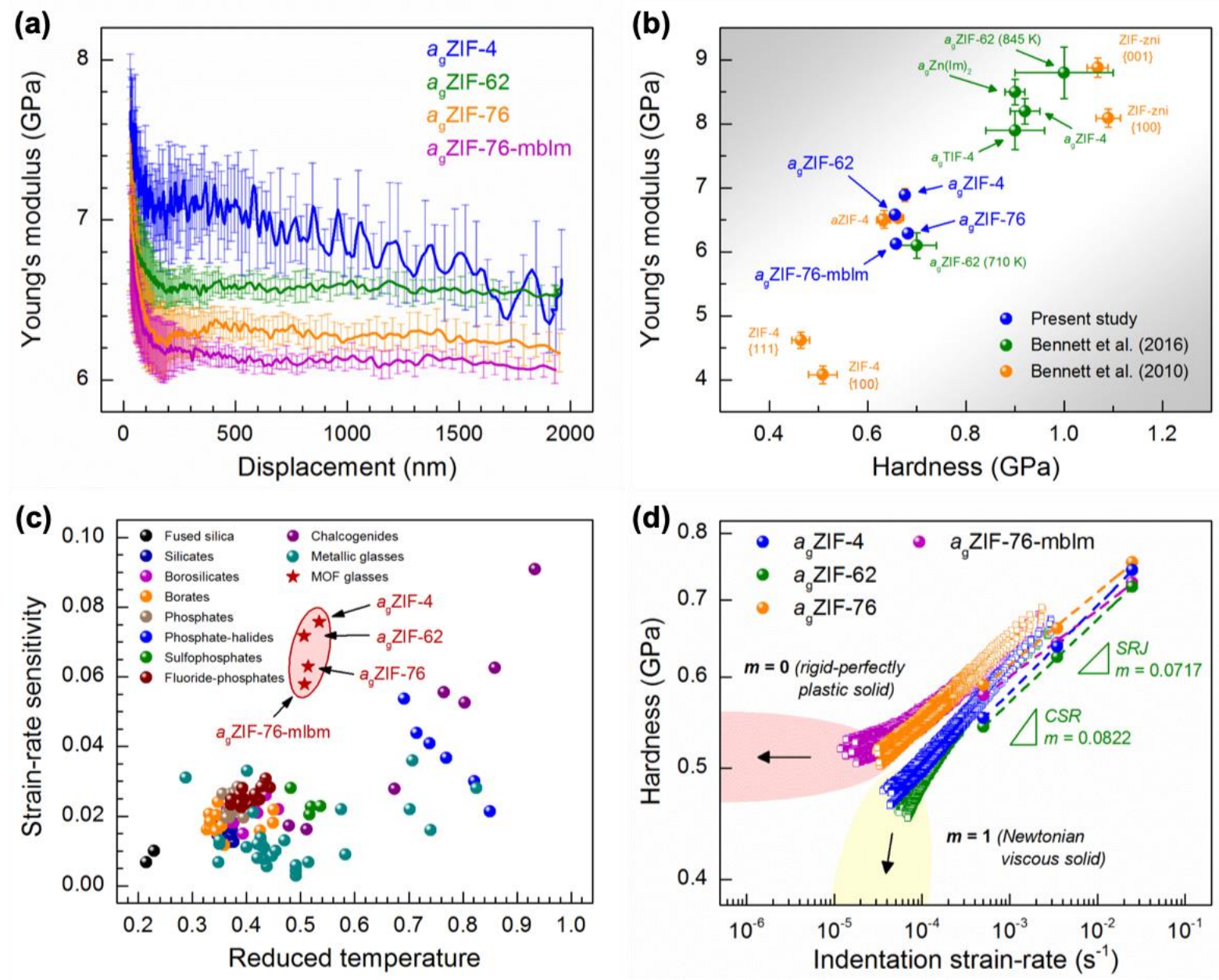

Figure 2. (a) Variation of Young's modulus as a function of the indenter displacement in melt-quenched $a_{\mathrm{g} Z I F-4,} a_{\mathrm{g} Z I F-62,} a_{\mathrm{g} Z I F-76}$ and $a_{\mathrm{g} Z I F-76-m b I m}$. (b) Correlation between Young's modulus and hardness for MOF glasses. Experimental results for crystalline and amorphous MOFs from previous studies are added for comparison. ${ }^{[16,27]}$ (c) Strain-rate sensitivity determined in nanoindentation strainrate jump (SRJ) tests plotted against the reduced temperature (i.e. testing temperature divided by the glass transition temperature) for the four melt-quenched MOF glasses. Literature data for inorganic ${ }^{[30,33,35-37]}$ and metallic glasses ${ }^{[38]}$ are added for comparison. (d) Relationship between hardness of the four melt-quenched MOF glasses and indentation strain-rate during SRJ testing and constant load and hold (CLH)

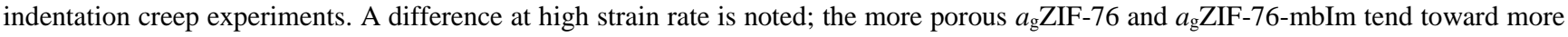
viscous behaviour, and the dense $a_{\mathrm{g}} \mathrm{ZIF}-4$ and $a_{\mathrm{g} Z \mathrm{IF}-62}$ tend toward plastic behaviour.

from the CLH experiments $(m=0.0636-0.0835)$ are slightly higher in comparison to the results of the SRJ tests, the compositional dependence of $m$ derived from both approaches agreed well at higher strain rates (Table 1). At lower strain rates however, a deviation from the linear correlation between the logarithm of the hardness, $\ln H$, and the logarithm of the indentation strain-rate, $\ln \dot{\varepsilon}_{\mathrm{i}}$, was noted (Fig. 2d). Deformation

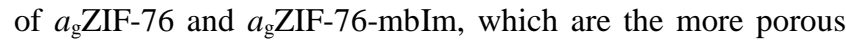
systems, tend towards a rigid, perfectly plastic behaviour, i.e., a rate-independent hardness $(m=0)$. Deformation of the dense

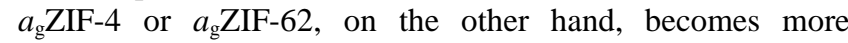
homogeneous, and approaches a Newtonian viscous flow behaviour $(m=1){ }^{[39]}$

A vital descriptor of the mechanical behaviour of glasses, in both academic and industrial contexts, is the resistance to scratching. In general, organic glasses are ductile, yet scratch prone, whilst inorganic glasses are brittle, though largely resistant to scratching. Such experiments on MOF glasses have in the past been entirely prohibited by the small size and inhomogeneous nature of samples produced using direct melt quenching.

A new processing methodology was thus sought, with the main objective to fabricate bulk, homogeneous and bubble-free MOF glasses. For this purpose, (i) vacuum hot-pressing and (ii) remelting of the pre-formed glass were attempted and ZIF-62 was selected as a suitable candidate for this, as it represents the MOF with the lowest known $T_{\mathrm{m}}$.

\section{Vacuum hot-pressing routes to bulk MOF-glasses}

A ZIF-62 sample of $200 \mathrm{mg}$ was synthesized following the procedure described in detail in Ref. ${ }^{[16]}$ A bespoke diffusion bonder with a stainless steel mould and a $10 \mathrm{~mm}$ diameter plunger (Fig. S8 \& S9) was used to heat the sample to a temperature of $723 \mathrm{~K}$ under a pressure of $15 \mathrm{MPa}$ in vacuum. After 1 hour, the sample was removed from the press and an Xray amorphous sample was achieved, which is hereby referred to as $a_{\mathrm{gp}}$ ZIF-62 (the subscript 'gp' indicates a pressed glass) (Fig. 3a). Solution ${ }^{1} \mathrm{H}$ nuclear magnetic resonance (NMR) 
(a)
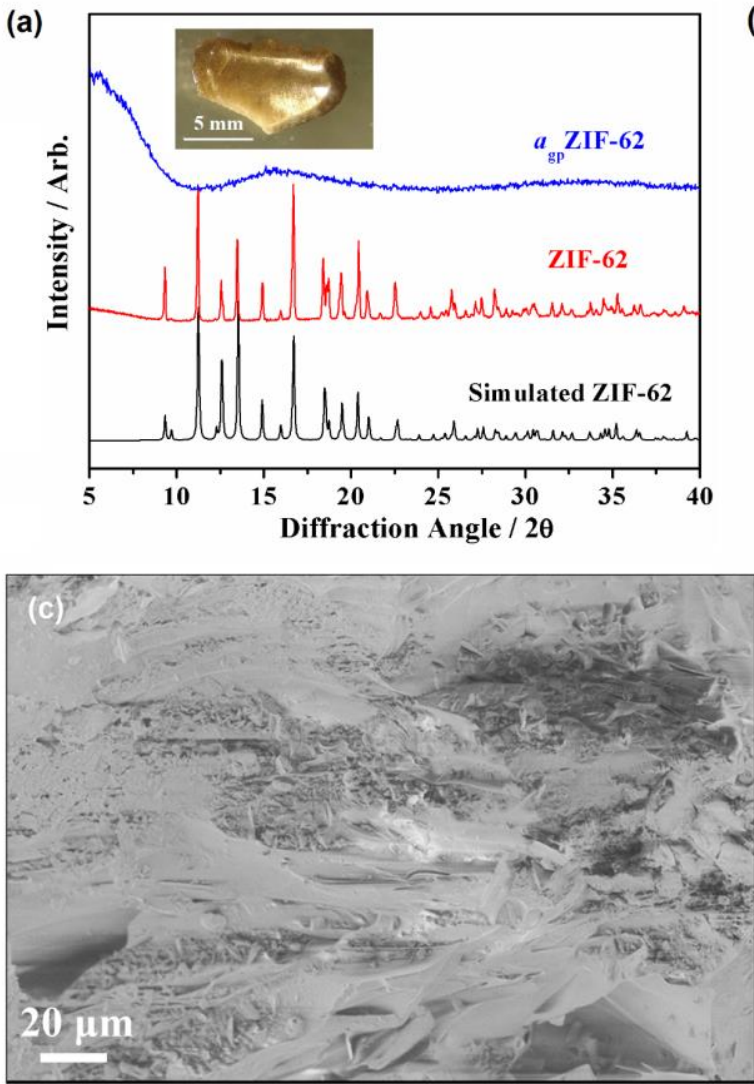

(b)
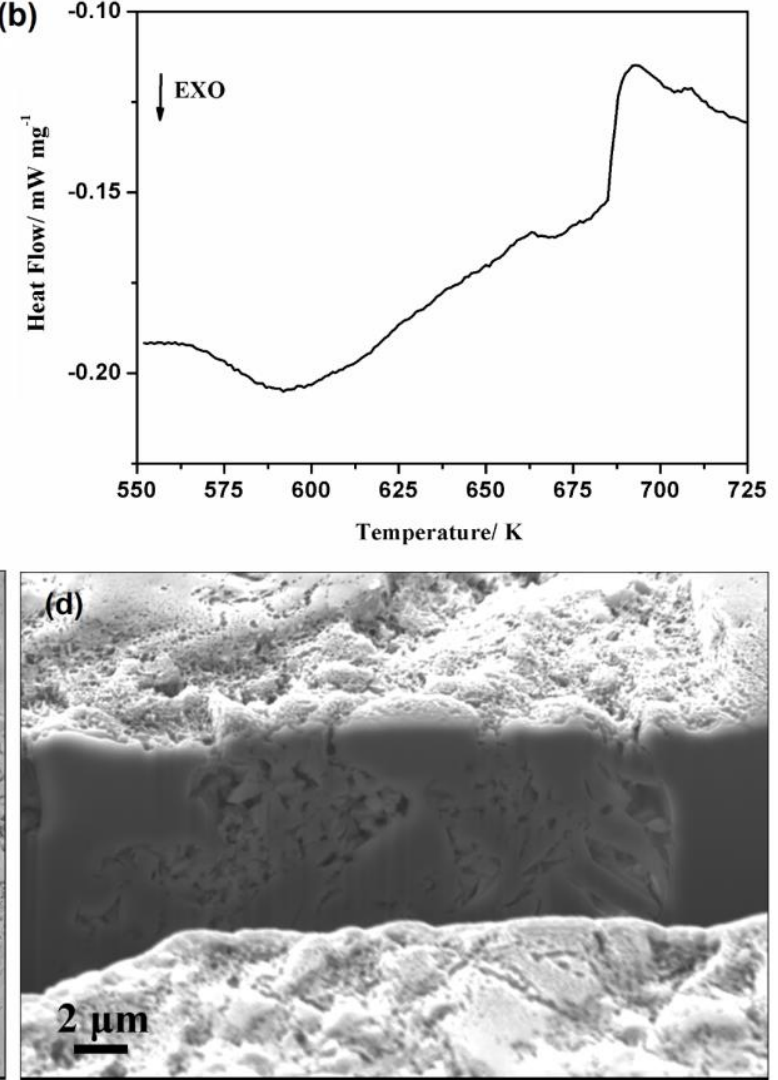

Figure 3. (a) Powder X-ray diffraction pattern (XRD) and optical image (inset) of $a_{\mathrm{gp}} Z \mathrm{IF-} 62$ formed by vacuum hot-pressing. (b) Differential scanning calorimetry (DSC) performed on two samples cut from different regions of the same $a_{\mathrm{gp}} \mathrm{ZIF}-62$. Scanning electron microscopic (SEM) images of $a_{\mathrm{gp}} \mathrm{ZIF}-62(\mathbf{c})$ before and (d) after a trench was cut into the sample using a focused ion beam (FIB).

spectroscopy confirmed the presence of the Im and bIm ligands in their expected ratios in both ZIF-62 and $a_{\mathrm{gp}}$ ZIF-62 (Fig. S10).

Differential scanning calorimetry (DSC) was conducted on a sample cut from the $a_{\mathrm{gp}}$ ZIF-62 specimen (Fig. 3b). An endothermic feature ascribed to melting was observed, as expected, at around $700 \mathrm{~K}$. This result suggests the bulk $a_{\mathrm{gp}} \mathrm{ZIF}$ 62 specimen is not composed purely of melt-quenched $a_{\mathrm{g} Z I F-}$ 62. Combined with the lack of Bragg peaks in the XRD pattern, the results may suggest that the sample is a mixture of amorphous, non-melt-quenched ZIF-62 (aZIF-62), and the melt quenched glass. The non-melt quenched system has previously been observed to exist prior to melting. ${ }^{[16]}$ The presence of aZIF-62 indicates the existence of a non-uniform temperature distribution inside the sample during vacuum hot-pressing.

Scanning electron microscopy (SEM) was performed on a bulk sample of $a_{\mathrm{gp}}$ ZIF-62 (Fig. 3c), revealing significant variations in material density across the surface. To explore the internal microstructure, focused ion beam (FIB) milling was performed to cut a trench into the sample, which revealed an inhomogeneous interior with similar variations in density to the surface (Fig. 3d). Distinct particle-like objects are observable, indicating that ZIF-62 crystallites near to the surface may have coalesced during vacuum hot-pressing, though this was not the case throughout the sample. This inhomogeneity supports the existence of both $a \mathrm{ZIF}-62$ and $a_{g} \mathrm{ZIF}-62$.
Nanoindentation experiments were conducted to analyse the mechanical stability of $a_{\mathrm{gp}}$ ZIF-62 (Fig. S11). The loaddisplacement curves exhibit a smooth and parabolic shape without any discontinuities. However, due to the inhomogeneous microstructure of $a_{\mathrm{gp}} \mathrm{ZIF}-62$ (Fig. S12), the maximum indenter displacements at peak loads of $5 \mathrm{mN}$ varied between 760 and $2053 \mathrm{~nm}$. A detailed inspection of the loaddisplacement data further reveal a rapid increase of the indentation depth during the holding segment at the maximum load, providing more evidence of the poor resistance to creep of this sample. Along with these fluctuations in indenter displacement, the obtained values of $E=(3.2 \pm 1.4) \mathrm{GPa}$ and $H$ $=(0.37 \pm 0.25) \mathrm{GPa}$ scatter significantly. A critical appraisal of the present findings is therefore strongly limited, though the values of $E$ and $H$ indicate a lower mechanical stability of $a_{\mathrm{gp}} \mathrm{ZIF}-62$ as compared to MOF glasses prepared by meltquenching or thermal collapse. ${ }^{[16,27,28]}$

\section{Remelting as a route to homogeneous, bulk MOF-glasses}

The failure of vacuum hot-pressing to fabricate a bulk glass of sufficient quality for scratch testing led us to consider an alternative preparation route. Previous methods of $a_{\mathrm{g}} \mathrm{ZIF}-62$ production rely on heating a crystalline sample of ZIF-62 to $T_{\mathrm{m}}$, followed by melt-quenching. This however results in numerous bubbles in the final $a_{\mathrm{g}}$ ZIF-62 specimen (Fig. S13). The presence of bubbles in glasses is commonly regarded as a serious flaw, ${ }^{[40]}$ yet their formation in $a_{\mathrm{g}}$ ZIF-62 is encouraged by the high 

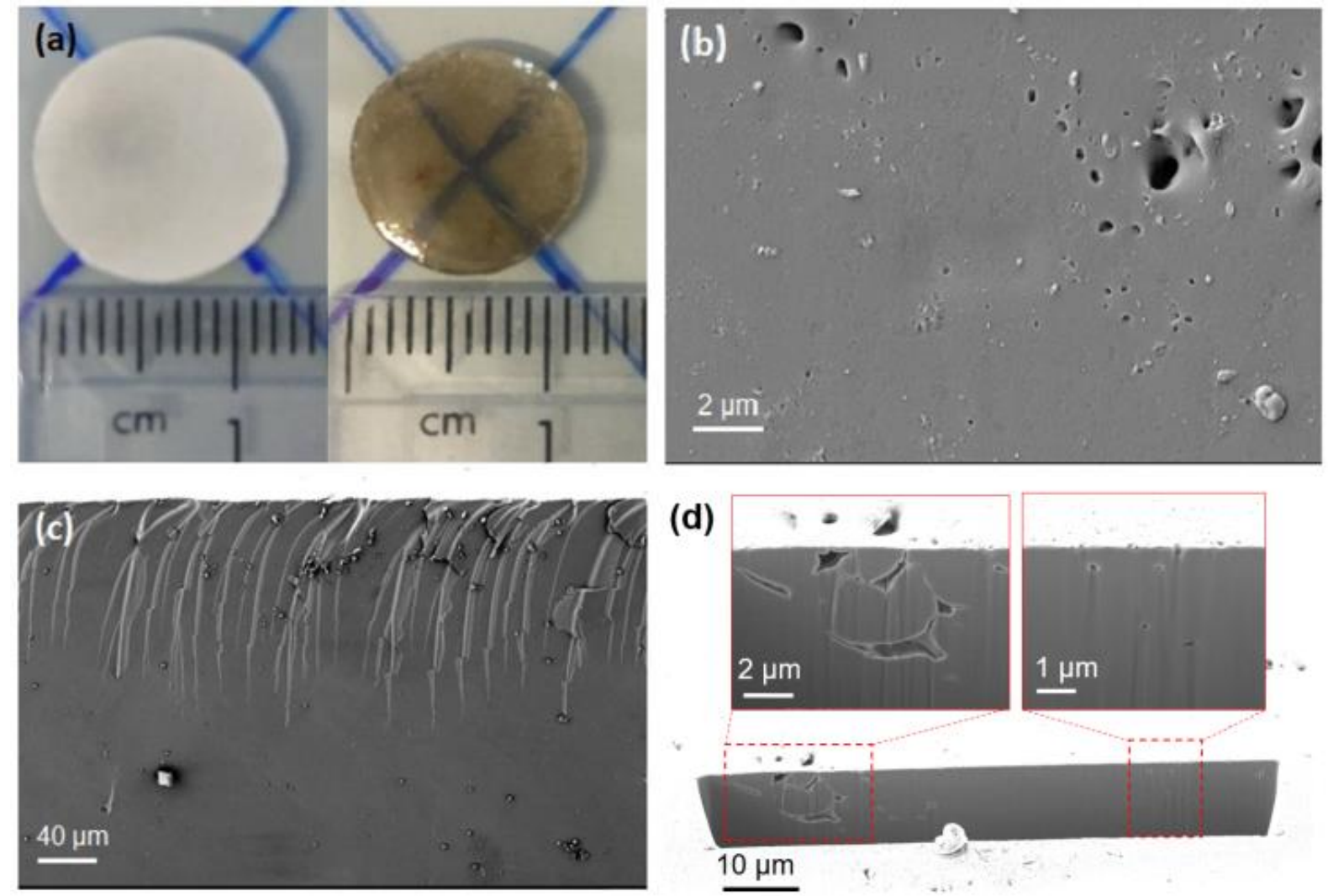

Figure 4. (a) Optical photographs of $a_{\mathrm{g} Z \mathrm{ZIF}-62}$ before (left) and after (right) remelting ( $a_{\mathrm{gr}}$ ZIF-62), respectively. (b) Scanning electron microscopic (SEM) images of the surface and (c) cross-section morphology of $a_{\mathrm{gr}}$ ZIF-62. (d) A trench cut into $a_{\mathrm{gr}} \mathrm{ZIF}-62$ using a focused ion beam (FIB).

viscosity of the ZIF-62 liquid at around $T_{\mathrm{m}}{ }^{[23]}$ This tendency for bubble formation is correlated with partial decomposition of ZIF-62 at high temperature, as continuous weight loss was observed for ZIF-62 at $700 \mathrm{~K}$ (Fig. S14(a)). However, no mass loss from ZIF-62 was observed when the sample is held at 670 K (Fig. S14(b)). Thus, remelting a sample of $a_{\mathrm{g}} \mathrm{ZIF}-62$ at a temperature above $T_{\mathrm{g}}(591 \mathrm{~K})$ but below $700 \mathrm{~K}$, was attempted to circumvent the presence of bubbles in bulk samples. For this purpose, crystalline ZIF-62 was first heated up to $723 \mathrm{~K}$ without an isothermal segment, and naturally cooled to room

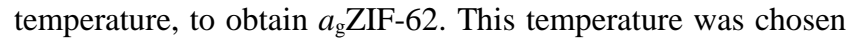
as it is above the melting temperature of ZIF-62 $(710 \mathrm{~K}),{ }^{[16]}$ and the time selected in order to avoid the mass loss observed upon isothermal treatment. The sample was then ball-milled along with $2 \times 7 \mathrm{~mm}$ stainless steel balls at $25 \mathrm{~Hz}$ for 5 minutes, to homogenize particle size, and subsequently pressed into a pellet with diameter of $13 \mathrm{~mm}$, in order to place grain surfaces in close proximity to one another. After that, the $a_{\mathrm{g}} \mathrm{ZIF}-62$ pellet was heated to $673 \mathrm{~K}$, i.e. above $T_{\mathrm{g}}$, for 5 hours. At this temperature, unlike at $700 \mathrm{~K}$, no isothermal mass loss was observed (Fig. S12b). The final glass, referred to as $a_{\mathrm{gr}} \mathrm{ZIF}-62$, was transparent, of thickness $0.95 \pm 0.01 \mathrm{~mm}$, and, most notably, largely free of bubbles (Fig. 4a and Fig. S15).

DSC curves recorded from samples before $\left(a_{\mathrm{g}} \mathrm{ZIF}-62\right)$ and after remelting $\left(a_{\mathrm{gr}}\right.$ ZIF-62) suggest a similar $T_{\mathrm{g}}$ at around $600 \mathrm{~K}$ (Fig. S16), consistent with that observed previously. ${ }^{[16]}$ The

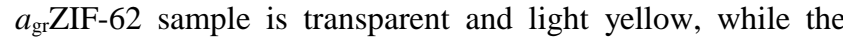
$a_{\mathrm{g} Z I F-62}$ pellet is opaque white (Fig. 4a). The curved surface of $a_{\mathrm{gr}} \mathrm{ZIF}-62$ indicates a large surface tension of the liquid ZIF62 at temperatures above $T_{\mathrm{g}}$, which is the driving force for the formation of dense and transparent $a_{\mathrm{gr}} \mathrm{ZIF}-62$ during the process of remelting. SEM images (Fig. 4b-d) of $a_{\mathrm{gr}} \mathrm{ZIF}-62$ indicate a dense $a_{\mathrm{gr}}$ ZIF-62 specimen with few surface defects. Some surface macroscale pores can be seen in Fig. 4b, though otherwise the surface is smooth and continuous. Fig. $4 \mathbf{c}$ shows the bulk structure exposed over a large area by fracture of the sample. The original surface is the bright area at the top of the image. Curved ring-cracks, consistent with brittle fracture extend from the surface into the middle of the field of view. Macroscale pores or defects were not observed inside the bulk specimen (Fig. 4c). FIB sectioning very close to the original surface showed some limited porosity (Fig. 4d), which consequently explains the generation of pores on the surface of $a_{\mathrm{gr}} \mathrm{ZIF}-62$. The thickness of the sample was $0.95 \pm 0.01 \mathrm{~mm}$.

The successful fabrication of a homogeneous bulk $a_{\mathrm{gr}} \mathrm{ZIF}-62$ specimen allowed us, for the first time, to perform scratch experiments on a MOF glass. For this purpose, ramp-load scratch tests (Fig. 5a) and indentations (Fig. 5b) with maximum loads of 1,10 and $50 \mathrm{mN}$, respectively, were produced by means of a conical diamond indenter with an opening angle, $\theta$, of $60^{\circ}$ and an effective tip radius, $R$, of $5.15 \mu \mathrm{m}$. The scratch response of other glasses when using a spherical indenter tip is, in general, characterized by a fully elastic deformation at low loads. With a further load increment, yield, and then subsequent ductile fracture occurs. The latter manifests in an abrupt increasing friction coefficient, $\mu$ (i.e. the lateral force required 

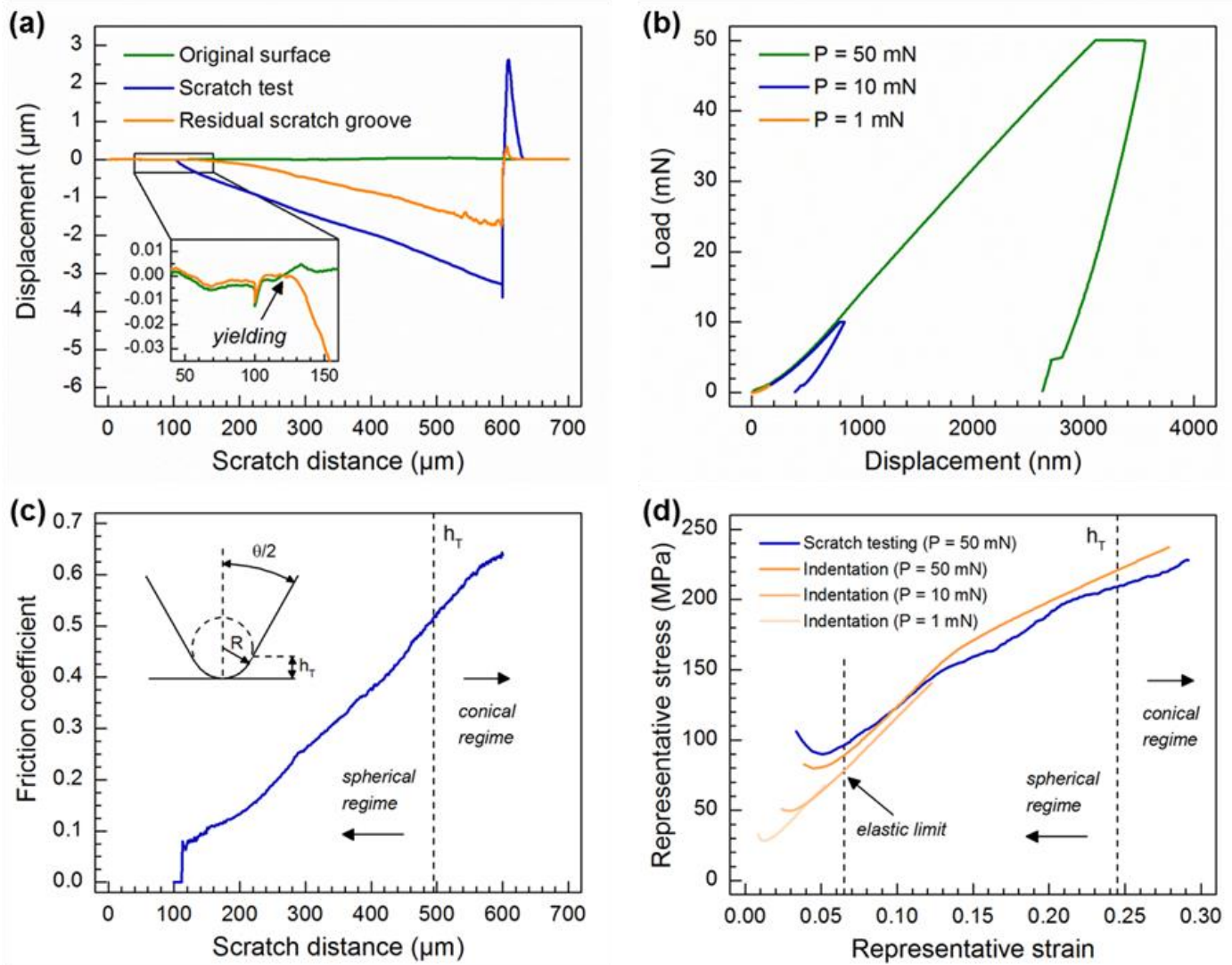

Figure 5. (a) Example ramp-load scratch test on $a_{\mathrm{gr}} \mathrm{ZIF}-62$ performed with a conical diamond indenter with a $60^{\circ}$ tip angle and an effective radius of $5.15 \mu \mathrm{m}$. The scratch test was conducted across a distance of $500 \mu \mathrm{m}$ at a scratch speed of $50 \mu \mathrm{m} / \mathrm{s}$ and under monotonically increasing loads up to $50 \mathrm{mN}$. (b) Representative nanoindentation load-displacement curves of $a_{\mathrm{gr}} Z \mathrm{IF}-62$. Indentations with loads of 1,10 and $50 \mathrm{mN}$, respectively, were generated using the aforementioned conical diamond indenter. A constant loading duration of $10 \mathrm{~s}$ and a $5 \mathrm{~s}$ dwell time at maximum load was utilized in all experiments. (c) Change in friction coefficient during scratch testing. (d) Representative stress-strain curves determined by nanoindentation and scratch testing on

to move the indenter tip across the sample surface divided by the load applied), as well as in the formation of massive amounts of debris. ${ }^{[41]}$

The onset of yielding in $a_{\mathrm{gr}} \mathrm{ZIF}-62$ is clearly discernible from a comparison of the surface profiles before and after scratching (Fig. 5a). However, in stark contrast to previous observations on inorganic ${ }^{[41]}$ and metallic glasses ${ }^{[42]}$, no ductile fracture is seen within the limits of spherical scratch testing. This is evident from the absence of sudden jumps in the friction coefficient, $\mu$, curve, which was simultaneously recorded to $h$ during the monotonic load increase (Fig. 5c). To facilitate a critical assessment of the materials response to normal indentation and lateral deformation, representative stressstrains curves obtained by nanoindentation and scratch testing are plotted together in Figure 5d. The similarity of these curves suggests the activation of equivalent deformation modes during normal indentation and lateral deformation. This result is in agreement with very recent findings reported for inorganic glasses, where it was found that the relative contribution of the prevailing deformation mechanism (densification and volumeconservative shear flow) is strongly dependent on network topology so that ratio between lateral and normal hardness may very over a broad range. ${ }^{[43,44]}$

To show the generalality of the remelting technique in producing a bulk, homogeneous sample, we also heated a sample of ZIF-4 to $c a .863 \mathrm{~K}$ in an argon atmosphere (i.e. above $T_{\mathrm{m}}$ ), without isothermal treatment, and cooled naturally to room temperature. Consistent with previous literature, discolouration was observed due to the small temperature region between melting and decomposition (ca $2 \mathrm{~K}$ ), ${ }^{[16]}$ This glass was then ground, and pressed into a pellet with a diameter of $5 \mathrm{~mm}$ and a thickness of $1 \mathrm{~mm}$. This was then heated at $673 \mathrm{~K}$ (i.e. above $T_{\mathrm{g}}$ ) under Ar, for 5 hours.

The product obtained was a bulk sample, (Fig. S17). Interestingly, it was also partially crystalline (Fig. S18), and Xray diffraction indicated the presence of the dense ZIF-zni framework. ${ }^{[16]}$ This result is therefore notable, in that it also shows the remelting technique can, providing the appropriate starting materials are chosen, be used to create a bulk, robust, crystalline sample.

\section{CONCLUSIONS}

The Young's modulus, hardness and strain-rate sensitivity of four melt-quenched MOF glasses: $a_{\mathrm{g} Z I F-4,} a_{\mathrm{g} Z I F-62,} a_{\mathrm{g} Z I F-76}$ and $a_{\mathrm{g} Z I F-76-m b I m}$ were studied by nanoindentation. The strain-rate sensitivity was determined in strain-rate jump (SRJ) tests and through constant load and hold (CLH) indention creep experiments. The results obtained from both methods agree well and values of the strain-rate sensitivity of melt-quenched MOF glasses were found to be close to the values reported for glassy polymers and Se-rich GeSe chalcogenide glasses with 
comparable hardness values. With (i) vacuum hot-pressing and (ii) remelting, two new routes for the preparation of homogeneous MOF glasses in a larger scale were explored. The $a_{\mathrm{gp}} \mathrm{ZIF}-62$ formed by vacuum hot-pressing is composed of a mixture of melt-quenched $a_{\mathrm{g}} \mathrm{ZIF}-62$ and amorphous, non-meltquenched aZIF-62 and, by extension, possesses an inhomogeneous microstructure along with a poor mechanical stability. In contrast, a transparent and bubble-free bulk glass sample of $a_{\mathrm{gr}}$ ZIF-62 was successfully fabricated by remelting. Ramp-load scratch tests were carried out on the latter to investigate the scratch resistance of MOF glasses.

A comparison between the representative stress-strain curves determined by nanoindentation and scratch testing suggests the activation of similar deformation mechanisms during normal indentation and lateral deformation, and the absence of ductile fracture, which is in stark contrast to inorganic glasses. In accordance with a recent hypothesis on the role of structural heterogeneity in local deformation processes, the mechanical response of MOF-glasses appears to be largely determined by super-structural parameters and the associated fluctuations in network rigidity. ${ }^{[45]}$ performed The scratch-behaviour measurement of which was only made possible by the production of bulk samples here - may be highly promising for applications in coatings, displays or applications where scratch resistant, non-brittle surfaces are required.

In summary, these results are highly promising and yield both necessary, and valuable insights into the potential applications of this new category of melt-quenched glasses.

\section{ASSOCIATED CONTENT}

Supporting Information. This document contains materials and methods, results of XRD, nanoindentation, scratch testing, ${ }^{1} \mathrm{H}$ NMR, wild-field confocal microscopy, TGA and DSC, schematic illustration of the diffusion bonder, and photographs of the diffusion bonder and bulk MOF glass samples. This material is available free of charge via the Internet at http://pubs.acs.org.

\section{AUTHOR INFORMATION}

\section{Corresponding Author \\ *tdb35@cam.ac.uk}

\section{ACKNOWLEDGMENT}

T.D.B. would like to thank the Royal Society for a University Research Fellowship (RG82023) and EPSRC (EP/R015481/1). T.D.B. would also like to thank the Royal Society for a Research Grant (RG94426). S.L. acknowledges China Scholarship Council (CSC). L.L. acknowledges an EPSRC studentship. L.W. acknowledges support from the European Research Council through grant no. 681652. P.A.M. thanks the EPSRC for financial support under grant number EP/R025517/1.

\section{REFERENCES}

[1] Park, K. S.; Ni, Z.; Côté, A. P.; Choi, J. Y.; Huang, R.; UribeRomo, F. J.; Chae, H. K.; O’Keeffe, M.; Yaghi, O. M. Exceptional chemical and thermal stability of zeolitic imidazolate frameworks. PNAS 2006, 103, 10186.

[2] Tian, Y.-Q.; Zhao, Y.-M.; Chen, Z.-X.; Zhang, G.-N.; Weng, L.-H.; Zhao, D.-Y. Design and generation of extended zeolitic metal-organic frameworks (ZMOFs): Synthesis and crystal structures of zinc(II) imidazolate polymers with zeolitic topologies. Chem. Eur. J. 2007, 13, 4146.

[3] Phan, A.; Doonan, C. J.; Uribe-Romo, F. J.; Knobler, C. B.; O'Keeffe, M.; Yaghi, O. M. Structure, and carbon dioxide capture properties of zeolitic imidazolate frameworks. Acc. Chem. Res. 2010, 43, 58.

[4] Karagiaridi, O.; Lalonde, M. B.; Bury, W.; Sarjeant, A. A.; Farha, O. K.; Hupp, J. T. Opening ZIF-8: A catalytically active zeolitic imidazolate framework of sodalite topology with unsubstituted linkers. J. Am. Chem. Soc. 2012, 134, 18790 .

[5] Fei, H.; Cahill, J. F.; Prather, K. A.; Cohen, S. M. Tandem postsynthetic metal ion and ligand exchange in zeolitic imidazolate frameworks. Inorg. Chem. 2013, 52, 4011.

[6] Yang, J.; Zhang, Y.-B.; Liu, Q.; Trickett, C. A.; GutiérrezPuebla, E.; Monge, M. Á.; Cong, H.; Aldossary, A.; Deng, H.; Yaghi, O. M. Principles of designing extra-large pore openings and cages in zeolitic imidazolate frameworks. $J$. Am. Chem. Soc. 2017, 139, 6448.

[7] Kertik, A.; Wee, L. H.; Pfannmöller, M.; Bals, S.; Martens, J. A.; Vankelecom, I. F. J. Highly selective gas separation membrane using in situ amorphised metal-organic frameworks. Energy Environ. Sci. 2017, 10, 2342.

[8] Su, Z.; Shaw, W. L.; Miao, Y.-R.; You, S.; Dlott, D. D.; Suslick, K. S. Shock wave chemistry in a metal-organic framework. J. Am. Chem. Soc. 2017, 139, 4619.

[9] Wu, T.; Feng, X.; Elsaidi, S. K.; Thallapally, P. K.; Carreon, M. A. Zeolitic imidazolate framework-8 (ZIF-8) membranes for $\mathrm{Kr} / \mathrm{Xe}$ separation. Ind. Eng. Chem. Res. 2017, 56, 1682.

[10] Han, C.; Zhang, C.; Tymińska, N.; Schmidt, J. R.; Sholl, D. S. Insights into the stability of zeolitic imidazolate frameworks in humid acidic environments from firstprinciples calculations. J. Phys. Chem. C 2018, 122, 4339.

[11] Bourg, L. B. d.; Ortiz, A. U.; Boutin, A.; Coudert, F.-X. Thermal and mechanical stability of zeolitic imidazolate frameworks polymorphs. APL Mater. 2014, 2, 124110.

[12] Tan, J.C.; Bennett, T.D.; Cheetham A.K. Chemical structure, network topology, and porosity effects on the mechanical properties of Zeolitic Imidazolate Frameworks. PNAS, 2010, 107, 9938.

[13] Banerjee, R.; Phan, A.; Wang, B.; Knobler, C.; Furukawa, H.; O'Keeffe, M.; Yaghi, O. M. High-throughput synthesis of zeolitic imidazolate frameworks and application to $\mathrm{CO}_{2}$ capture. Science 2008, 319, 939.

[14] Gustafsson, M.; Zou, X. Crystal formation and size control of zeolitic imidazolate frameworks with mixed imidazolate linkers. J. Porous Mater. 2013, 20, 55.

[15] Gaillac, R.; Pullumbi, P.; Beyer, K. A.; Chapman, K. W.; Keen, D. A.; Bennett, T. D.; Coudert, F.-X. Liquid metalorganic frameworks. Nat. Mater. 2017, 16, 1149.

[16] Bennett, T. D.; Yue, Y.; Li, P.; Qiao, A.; Tao, H.; Greaves, N. G.; Richards, T.; Lampronti, G. I.; Redfern, S. A. T.; Blanc, F.; Farha, O. K.; Hupp, J. T.; Cheetham, A. K.; Keen, D. A. Melt-quenched glasses of metal-organic frameworks. J. Am. Chem. Soc. 2016, 138, 3484.

[17] Widmer, R. N.; Lampronti, G. I.; Anzellini, S.; Gaillac, R.; Farsang, S.; Zhou, C.; Belenguer, A. M.; Palmer, H.; Kleppe, A. K.; Wharmby, M. T.; Redfern, S. A. T.; Coudert, F.-X.; Macleod, S. G.; Bennett, T. D. Pressure promoted lowtemperature melting of metal-organic frameworks. ChemRxiv, 2018, 10.26434/chemrxiv.6541190.v3.

[18] Zhou, C.; Longley, L.; Krajnc, A.; Smales, G. J.; Qiao, A.; Erucar, I.; Doherty, C. M.; Thornton, A. W.; Hill, A. J.; Ashling, C. W.; Qazvini, O. T.; Lee, S. J.; Chater, P. A.; Terrill, N. J.; Smith, A. J.; Yue, Y.; Mali, G.; Keen, D. A.; Telfer, S. G.; Bennett, T. D. Metal-organic framework glasses with permanent accessible porosity. Nat. Commun., 2018, 9, 5042 
[19] Umeyama, D.; Horike, S.; Inukai, M.; Itakura, T.; Kitagawa, S. Reversible solid-to-liquid phase transition of coordination polymer crystals. J. Am. Chem. Soc. 2015, 137, 864.

[20] Bennett, T.D.; Horike S. Liquid, glass and amorphous solid states of coordination polymers and metal-organic frameworks. Nat. Rev. Mater., 2018, 3, 431.

[21] Bennett, T.D.; Cao, S.; Tan, J.C.; Keen, D.A.; Bithell, E.G.; Beldon, P.J.; Friscic, T.; Cheetham, A.K. Facile mechanosynthesis of amorphous zeolitic imidazolate frameworks. J. Am. Chem. Soc. 2011, 133, 14546.

[22] Chapman, K.W.; Halder, G.J.; Chupas, P.J. Pressureinduced amorphization and porosity modification in a metal-organic framework. J. Am. Chem. Soc. 2009, 131, 17546.

[23] Qiao, A.; Bennett, T. D.; Tao, H.; Krajnc, A.; Mali, G.; Doherty, C. M.; Thornton, A. W.; Mauro, J. C.; Greaves, G. N.; Yue, Y. A metal-organic framework with ultrahigh glass-forming ability. Sci. Adv., 2018, $4,1$.

[24] Chen, Y.; Li, S.; Pei, X.; Zhou, J.; Feng, X.; Zhang, S.; Cheng, Y.; Li, H.; Han, R.; Wang, B. A solvent-free hotpressing method for preparing metal-organic-framework coatings. Angew. Chem. Int. Ed. 2016, 55, 3419.

[25] Widmer, R. N.; Lampronti, G. I.; Kunz, B.; Battaglia, C.; Shepherd, J. H.; Redfern, S. A. T.; Bennett, T. D. Manufacturing macroporous monoliths of microporous MOFs. ACS Appl. Nano Mater. 2018, 1, 497.

[26] Chen, W.; Horike, S.; Umeyama, D.; Ogiwara, N.; Itakura, T.; Tassel, C.; Goto, Y.; Kageyama, H.; Kitagawa, S. Glass formation of a coordination polymer crystal for enhanced proton conductivity and material flexibility. Angew. Chem. Int. Ed. 2016, 55, 5195.

[27] Bennett, T. D.; Goodwin, A. L.; Dove, M. T.; Keen, D. A.; Tucker, M. G.; Barney, E. R.; Soper, A. K.; Bithell, E. G.; Tan, J.-C.; Cheetham, A. K. Structure and properties of an amorphous metal-organic framework. Phys. Rev. Lett. 2010, 104, 115503.

[28] Bennett, T. D.; Keen, D. A.; Tan, J.-C.; Barney, E. R.; Goodwin, A. L.; Cheetham, A. K. Thermal amorphization of zeolitic imidazolate frameworks. Angew. Chem. Int. Ed. 2011, 50, 3067.

[29] Sudharshan Phani, P.; Oliver, W. C.; Pharr, G. M. On the measurement of power law creep parameters from instrumented indentation. JOM 2017, 69, 2229.

[30] Limbach, R.; Rodrigues,B. P.; Wondraczek, L.; Strain-rate sensitivity of glasses. J. Non-Cryst. Solids 2014, 404, 124.

[31] Chu, S. N. G.; Li, J. C. M. Impression creep; a new creep test. J. Mater. Sci. 1977,12, 2200.

[32] Kermouche, G.; Loubet, J. L.; Bergheau, J. M. Extraction of stress-strain curves of elastic-viscoplastic solids using conical/pyramidal indentation testing with application to polymers. Mech. Mater. 2008, 40, 271.
[33] Guin, J. P.; Rouxel, T.; Keryvin, V.; Sangleboeuf, J. C.; Serre, I.; Lucas, J. Indentation creep of $\mathrm{Ge}-\mathrm{Se}$ chalcogenide glasses below $\mathrm{T}_{\mathrm{g}}$ : elastic recovery and non-Newtonian flow J. Non-Cryst. Solids 2002, 298, 260.

[34] Meinhard, H.; Grau, P.; Berg, G.; Mosch, S. Hardness and flow behaviour of glass in the nanometre range-an interpretation of the load dependence of the hardness Glass Sci. Technol. 1997, 70, 333.

[35] Limbach, R.; Rodrigues, B. P.; Möncke, D.; Wondraczek, L. Elasticity, deformation and fracture of mixed fluoridephosphate glasses. J. Non-Cryst. Solids 2015, 430, 99.

[36] Möncke, D.; Kamitsos, E. I.; Palles, D.; Limbach, R.; Winterstein-Beckmann, A.; Honma, T.; Yao, Z.; Rouxel, T.; Wondraczek, L. Transition and post-transition metal ions in borate glasses: Borate ligand speciation, cluster formation, and their effect on glass transition and mechanical properties J. Chem. Phys. 2016, 145, 124501.

[37] Limbach, R.; Karlsson, S.; Scannell, G.; Mathew, R.; Edén, M.; Wondraczek, $\mathrm{L}$. The effect of $\mathrm{TiO}_{2}$ on the structure of $\mathrm{Na}_{2} \mathrm{O}-\mathrm{CaO}-\mathrm{SiO}_{2}$ glasses and its implications for thermal and mechanical properties J. Non-Cryst. Solids 2017, 471, 6.

[38] Limbach, R.; Kosiba, K.; Pauly, S.; Kühn, U.; Wondraczek, L. Serrated flow of CuZr-based bulk metallic glasses probed by nanoindentation: Role of the activation barrier, size and distribution of shear transformation zones J. Non-Cryst. Solids 2017, 459, 130.

[39] Goodall, R.; Clyne, T. W. A critical appraisal of the extraction of creep parameters from nanoindentation data obtained at room temperature. Acta Mater. 2006, 54, 5489.

[40] Shelby, J.E., Introduction to glass science and technology. Second ed. 2005: Royal Society of Chemistry.

[41] Lee, K.; Marimuthu, K. P.; Kim, C. L.; Lee, H. Scratch-tipsize effect and change of friction coefficient in nano / micro scratch tests using XFEM. Tribol. Int. 2018,120, 398.

[42] Michler, J.; Rabe, R.; Bucaille, J. L.; Moser, B.; Schwaller, P.; Breguet,; J. M. Investigation of wear mechanisms through in situ observation during microscratching inside the scanning electron microscope. Wear 2005, 259, 18.

[43] Sawamura, S.; Wondraczek, L.; Scratch hardness of glass. Phys. Rev. Mater. 2018, 2, 092601.

[44] Moayedi, E.; Sawamura, S.; Hennig, J.; Gnecco, E.; Wondraczek, L. Relaxation of scratch-induced surface deformation in silicate glasses: Role of densification and shear flow in lateral indentation experiments. J. Non-Cryst. Solids 2018, 500, 382.

[45] Benzine, O.; Bruns, S.; Pan, Z.; Durst, K.; Wondraczek, L. Local deformation of glasses is mediated by rigidity fluctuation on nanometer scale. Adv. Sci. 2018, 5, 1800916. 


\section{Table of Contents}

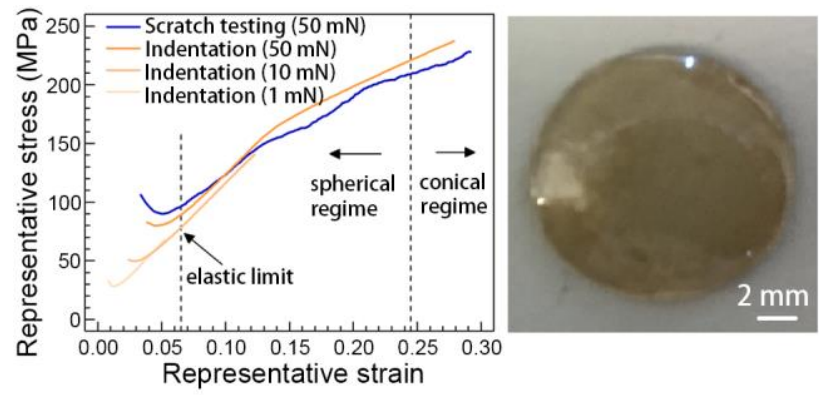

